Gut, 1977, 18, 136-140

\title{
Human intestinal ion transport in vitro
}

\author{
C. L. CORBETT, P. E. T. ISAACS, A. K. RILEY, AND L. A. TURNBERG 1 \\ From the Department of Medicine, Hope Hospital, University of Manchester School of Medicine, Salford
}

SUMMARY The transport of sodium and chloride across human jejunal and ileal mucosa was studied using an in vitro technique. Specimens of mucosa removed at operation were stripped of muscle coats, mounted in specially designed Perspex flux chambers and bathed in warmed oxygenated and stirred buffer solutions.

Evidence was obtained for the active transport of sodium in both jejunum and ileum and of chloride in the ileum. Sodium absorption was enhanced by glucose in both regions of the gut but net chloride transport was unaffected. Glucose had a greater effect on sodium transport in the ileum than the jejunum.

The electrical potential difference and resistance was greater and undirectional ion fluxes smaller in jejunal than ileal mucosa.

Many of these results with human intestine are similar to results reported with in vitro animal intestine. Apparent discrepancies between the behaviour in vivo of human intestine and in vitro of animal intestine are thus likely to be due predominantly to technical rather than species differences.

Much current information about mechanisms of intestinal electrolyte transport rests on the results of in vitro investigations using animal intestine. Human intestinal ion transport on the other hand has been studied mainly by in vivo techniques and relatively few in vitro investigations have been undertaken. Such discrepant observations as the failure of glucose to enhance sodium absorption in vivo in human ileum (Fordtran et al., 1968) but not in vitro in the rabbit ileum (Schultz and Zalusky, 1964b) and the failure to demonstrate bicarbonate absorption in vitro in rabbit jejunum (Fromm, 1973), while in vivo in man it clearly occurs (Fordtran et al., 1968), could be due to species differences or to technical variations. The present human in vitro studies were undertaken for comparison with in vitro animal and in vivo human intestinal behaviour.

\section{Methods}

Human intestine was obtained from patients undergoing small bowel resection for a variety of gastrointestinal disorders. Ileum was mainly from

1Address for correspondence: Professor L. A. Turnberg, Hope Hospital (University of Manchester School of Medicine), Eccles Old Road, Salford M6 8HD, UK.

Received for publication 20 August 1976 patients with colonic carcinoma, ulcerative colitis, and Crohn's disease, and jejunum from patients undergoing reconstructive biliary or pancreatic surgery, and upper gastrointestinal anastomoses. A variety of drugs had been given to the patients preoperatively but none had received corticosteroids or immunosuppressive therapy for at least two months before operation. The main anaesthetic was usually halothane but premedication varied. Atropine, omnopon with scopolamine, and mepyramine with pethidine were most commonly given. The cooperation of the surgeon was enlisted to ensure that the time between devascularisation and removal of the bowel was as short as possible. A segment of the resected bowel was opened along its mesenteric border and any intestinal contents washed away with buffer solution. The bowel was then pinned out onto a cork board and the mucosa carefully dissected off the muscle and serosal coats, being moistened throughout this time with oxygenated buffer solution. The mucosa, immersed in chilled oxygenated buffer was transported to the laboratory for mounting in the flux chambers. The buffer solution used before mounting was identical with that employed in the subsequent experiment. The time between removal of the bowel from the patient and mounting seldom exceeded 20 minutes.

The stripped mucosal preparation was similar to that described by Field et al. (1971) and Nellans 
et al. (1974) and consisted of mucosa, lamina propria, muscularis mucosae, and occasional tags of submucosal tissue. Only mucosa which was normal on naked-eye examination was accepted, and normality was subsequently confirmed by histological examination.

The design of the flux chambers was based on that of Schultz and Zalusky (1964b), the mucosa being clamped between two Perspex half-chambers, exposing an area of $1.77 \mathrm{~cm}^{2}$ to separate $10 \mathrm{ml}$ volumes of warmed $\left(37^{\circ}\right)$ buffer solution. The chambers and reservoirs were waterjacketed to maintain a constant temperature, and oxygenation and stirring were accomplished by a gas-lift circulating system. The gas employed, a $95 \% \mathrm{O}_{2} / 5 \% \mathrm{CO}_{2}$ mixture, was bubbled through water to minimise evaporative loss. The composition of the buffer solution was $\mathrm{Na} 146, \mathrm{~K} \mathrm{4} \cdot 2, \mathrm{Ca} 0 \cdot 6, \mathrm{Mg} \mathrm{O} \cdot 6, \mathrm{Cl} 126$, $\mathrm{HCO}_{3} 27 \cdot 6, \mathrm{HPO}_{4} 0 \cdot 1, \mathrm{H}_{2} \mathrm{PO}_{4} 1.2 \mathrm{mmol}^{-1}(\mathrm{pH}$ 7.55-7.60). In some studies D-glucose $15 \mathrm{mmol} . \mathrm{1}^{-1}$ was present in both the mucosal and serosal solutions.

Histological examination of mucosal preparations incubated for up to $3 \frac{1}{2}$ hours in the flux chambers showed only slight oedema of the lamina propria at the villous tips. Electron microscopic examination of mucosa incubated in glucose-containing solutions showed dilated lateral intercellular spaces with intact tight junctional complexes. The viability of the mucosa over long periods was demonstrated by its ability to maintain a significant potential difference (PD) and short circuit current (SCC) for at least three hours, the PD increasing with the addition of glucose at this time, and declining rapidly on cessation of oxygenation or the addition of metabolic inhibitors. Electron microscopy showed a normal subcellular structure and intact organelles after three hours' incubation.

\section{ELECTRICAL MEASUREMENTS}

The PD across the mucosa was measured with matched calomel electrodes (EIL) immersed in saturated $\mathrm{KCl}$, and connected to a high-impedance digital voltmeter (Solartron A240). The calomel electrodes were connected to the chambers by two narrow-tipped saturated $\mathrm{KCl}$-in-agar bridges placed close to the mucosa. The diameter of the bridge tips was less than $0.5 \mathrm{~mm}$ to minimise diffusion of $\mathrm{KCl}$ into the bathing solutions. Electrolyte concentrations in the bathing solutions varied by less than $2 \%$ during the course of an experiment. The combined electrode and bridge junction potentials were determined before tissue mounting and rarely exceeded $0.5 \mathrm{mV}$. The mucosa was short-circuited by a current passed from an external dry battery via $\mathrm{Ag} / \mathrm{AgCl}$ electrodes immersed in saturated $\mathrm{KCl}$ to narrow-tipped bridges containing $\mathrm{NaCl}$
(1 mol.1 $\left.{ }^{-1}\right)$ positioned at opposite ends of the conical half-chambers. The current passed was measured by a microammeter (Scalamp) and adjusted manually at least every five minutes and usually more frequently. In all experiments corrections were made for the resistance to the fluid gap between the tips of the potential measuring electrodes as described by Field et al. (1971). Transepithelial resistance (R) was calculated from open circuit PD and SCC. Although this does not give an unequivocal estimate of resistance, it provides a reasonable approximation.

Rapid changes in PD, SCC, and R, similar to those described in rabbit ileum (Glew et al., 1973), occurred with both jejunal and ileal mucosa on mounting in the flux chambers. After a rapid initial rise, a fall in PD was seen in nearly all tissues followed by a second rise of variable magnitude. By 30 to $\mathbf{4 0}$ minutes after mounting, PD, SCC, and R had reached stable values and in the absence of stimulation declined slowly and linearly over the next two to three hours. Because of these early variations, electrical values quoted were taken at 50 minutes after mounting unless otherwise specified.

\section{RADIO-ISOTOPE FLUXES}

$1.5 \mu \mathrm{Ci}{ }^{22} \mathrm{Na}$ and $2.5 \mu \mathrm{Ci}{ }^{36} \mathrm{Cl}$ (Radiochemical Centre, Amersham, Bucks, England) were added to either the mucosal or serosal solutions and, after a 20 or $\mathbf{4 0}$ minute equilibration period, both mucosal and serosal reservoirs were serially sampled at 20 minute intervals, the volume removed being replaced with unlabelled buffer. Tissue pairs in which the electrical resistance differed by less than $25 \%$ were used to obtain net flux results, and their electrical parameters were averaged to yield single values for each tissue pair.

Samples were counted for ${ }^{22} \mathrm{Na}$ in an automatic well-type gamma counter (Wallac) together with a standard for ${ }^{22} \mathrm{Na}$. An aliquot of the sample was then transferred into $5 \mathrm{ml}$ Bray's solution for liquid scintillation counting (Nuclear Chicago Mk. II). The ${ }^{22} \mathrm{Na}$ gamma counts, multiplied by a factor for the relative efficiency of the two counters for ${ }^{22} \mathrm{Na}$, were then subtracted from the total beta counts to give the ${ }^{36} \mathrm{Cl}$ counts. All samples were counted to 10000 counts and the output of the gamma and beta counters was recorded on punched tape. The calculations were performed on a PDP 12 digital computer.

\section{CALCULATIONS}

Unidirectional fluxes of $\mathrm{Na}$ and $\mathrm{Cl}$ were calculated using an equation similar to that of Schultz and Zalusky (1964a). In the present studies both the mucosal and serosal reservoirs were serially sampled, 
hence the specific activity of the initially labelled solutions was recalculated for each sample. The equation used was as follows:

$$
J=\left(\frac{\mathbf{C}_{2}}{\mathrm{P}_{2}^{*}}-\frac{\mathrm{C}_{1}}{\mathrm{P}_{1}{ }^{*}}\right) \cdot \frac{\mathrm{V}}{\mathrm{At}}
$$

where $\mathrm{J}$ is the unidirectional flux of an ion, $\mathrm{C}_{1}$ and $\mathrm{C}_{2}$ are the activities (cpm.ml-1) of the unlabelled solution in consecutive samples, $\mathbf{P}_{\mathbf{1}}{ }^{*}$ and $\mathbf{P}_{2}{ }^{*}$ are the specific activities (cpm. ml $\left.{ }^{-1} \cdot \mu \mathrm{Eq}^{-1}\right)$ of the labelled solution in consecutive samples, $\mathrm{V}$ is the volume of the labelled reservoir $(10 \mathrm{ml}), A$ is the area of exposed mucosa $\left(1.77 \mathrm{~cm}^{2}\right)$, and $t$ is the interval between samples (hours).

Tissue resistance was calculated as $\frac{\mathrm{PD} \times \mathrm{A}}{\mathrm{SCC}}$.

Short circuit current in $\mu$ amps was converted to $\mu$ mol.cm ${ }^{-2} \cdot \mathrm{h}^{-1}$ by multiplying by a factor of 0.02108. $\left(\frac{3.6 \times 10^{3}}{\mathrm{AF}}\right.$ where $\mathrm{F}$ is the Faraday constant). This formula relates electrical current to total net ion flux.

Residual ion flux (JRnet), which is that part of the SCC (in $\mu$ mol.cm ${ }^{-2} \cdot \mathrm{h}^{-1}$ ) not accounted for by net movement of $\mathrm{Na}$ and $\mathrm{Cl}$, was calculated as $\mathrm{SCC}-(\mathrm{JNa}$ net $+\mathrm{JCl}$ net $)$.

All values are expressed as the mean \pm 1 standard error.

Statistical comparisons were performed by Student's $t$ test. Paired and unpaired analysis were performed where appropriate.

\section{Results}

The electrical characteristics of jejunal and ileal mucosa in glucose-free solutions are shown in Table 1. PD was significantly higher in the jejunum, while SCC was higher in the ileum. The calculated tissue resistance in jejunum was greater than that in the ileum. In both jejunum and ileum there was a significant net absorption of sodium in glucose-free solutions (Table 2). There was a small net secretion of chloride in the jejunum and ileum, neither value being significantly different from zero. The calculated residual ion flux was compatible with a small, insignificant absorption of an anion in the jejunum and with a significant secretion of an anion in the ileum. This is usually taken to indicate bicarbonate ion movement but could equally be due to movement of hydrogen ions in the opposite direction. It is unlikely, however, to be due to movement of other ions which are present only in small concentrations. The smaller unidirectional fluxes in the jejunum reflect the greater electrical resistance of jejunal tissues.

Table 1 Influence of glucose on potential difference, short circuit current, and tissue resistance in human jejunal and ileal mucosa

\begin{tabular}{llll}
\hline & $P D(\mathrm{mV})$ & $S C C\left(\mu A . \mathrm{cm}^{-2}\right)$ & $R\left(\mathrm{ohm} . \mathrm{cm}^{-2}\right)$ \\
\hline $\begin{array}{l}\text { No glucose } \\
\text { Jejunum } \\
\mathbf{n}=22\end{array}$ & $5.6 \pm 0.4$ & $70.6 \pm 4.3$ & $82.6 \pm 5.8$ \\
$\begin{array}{l}\text { Ileum } \\
\mathbf{n}=48\end{array}$ & $3.3 \pm 0.3$ & $89.9 \pm 6.1$ & $40.3 \pm 2.8$ \\
$\begin{array}{l}\mathbf{P} \\
\text { Glucose } \\
\text { Jejunum } \\
\mathbf{n}=49\end{array}$ & $<0.001$ & $<0.05$ & $<0.001$ \\
$\begin{array}{l}\text { Ileum } \\
\mathbf{n}=50\end{array}$ & $8.4 \pm 0.4$ & $181.9 \pm 12.2$ & $52.7 \pm 4.3$ \\
$\mathbf{P}$ & $\mathrm{NS}$ & $252.4 \pm 15.8$ & $36.5 \pm 1.6$ \\
\hline
\end{tabular}

$\mathrm{n}$ refers to number of pieces of mucosa. Usually four pieces were obtained from each operative specimen.

Table 2 Ion transport across human jejunal and ileal mucosa and influence of glucose on transport

\begin{tabular}{|c|c|c|c|c|c|c|c|c|}
\hline & $\mathrm{JNa} \mathrm{ms}$ & $J N a s m$ & JNa net & $\mathrm{JCl} \mathrm{ms}$ & $\mathrm{JCl} \mathrm{sm}$ & JCl net & $J R$ net & $S C C$ \\
\hline \multirow{6}{*}{$\begin{array}{l}\text { No glucose } \\
\text { Jejunum } \\
\mathbf{n}=7 \\
\text { Ileum } \\
\mathbf{n}=15 \\
\mathbf{P} \\
\text { Glucose } \\
\text { Jejunum } \\
\mathbf{n}=15 \\
\text { Ileum } \\
\mathbf{n}=15 \\
\mathbf{P}\end{array}$} & $6.5 \pm 1.2$ & $5 \cdot 2 \pm 1 \cdot 1$ & $+1.3 \pm 0.4^{*}$ & $4.8 \pm 1.0$ & $6.6 \pm 0.7$ & $-1.8 \pm 0.9 \dagger$ & $-0.7 \pm 0.7 \dagger$ & $2.4 \pm 0.4$ \\
\hline & $11 \cdot 3 \pm 0.6$ & $10 \cdot 1 \pm 0 \cdot 4$ & $+1.2 \pm 0.5^{*}$ & $9.7 \pm 0.6$ & $10.1 \pm 0.3$ & $-0.4 \pm 0.6 \dagger$ & $+1.3 \pm 0.5^{*}$ & $2.9 \pm 0.3$ \\
\hline & $<0.001$ & $<0.001$ & NS & $<0.001$ & $<0.001$ & NS & $<0.05$ & NS \\
\hline & $12 \cdot 9 \pm 1 \cdot 5$ & $7 \cdot 1 \pm 0.6$ & $+5.9 \pm 1.2$ & $7.9 \pm 0.9$ & $9.1 \pm 0.8$ & $-1.3 \pm 0.8 \dagger$ & $-0.3 \pm 0.8 \dagger$ & $6.8 \pm 0.7$ \\
\hline & $20 \cdot 2 \pm 1 \cdot 5$ & $8 \cdot 1 \pm 0.5$ & $+12 \cdot 1 \pm 1 \cdot 4$ & $11 \cdot 1 \pm 0.6$ & $9.5 \pm 0.7$ & $+1.6 \pm 0.7^{*}$ & $+0.1 \pm 0.7 \dagger$ & $10.6 \pm 1.0$ \\
\hline & $<0.005$ & NS & $<0.005$ & $<0.01$ & NS & $<0.02$ & NS & 0.01 \\
\hline
\end{tabular}

Jms indicates unidirectional flux from the mucosal to the serosal side of the tissue, Jsm the flux in the opposite direction, and Jnet the difference between these unidirectional fluxes. $+:$ absorption. - : secretion. All fluxes and SCC are given in $\mu \mathrm{mol} \cdot \mathrm{h}^{-1} \mathrm{~cm}^{-1}$.

$n=$ number of tissue pairs. Results from two or three consecutive $\mathbf{2 0}$ minute flux periods were averaged for each pair of tissues.

*significantly different from zero $P<0.05$.

tnot significantly different from zero. 


\section{EFFECT OF GLUCOSE}

In both jejunum and ileum glucose enhanced PD and SCC $(\mathrm{P}<0.001)$ (Table 1). Ileal resistance was unaffected, but in the jejunum the resistance was lowered by glucose $(P<0.001)$. This is reflected in greater unidirectional fluxes in the jejunum in the presence of glucose compared with those in glucosefree solutions. PD was similar in jejunum and ileum in the presence of glucose, while SCC was higher in ileum. Resistance was again greater in the jejunum than the ileum.

Glucose increased net sodium absorption in jejunum $(\mathbf{P}<0.02)$ and ileum $(\mathbf{P}<0.001)$ mainly because of an increase in the mucosa to serosa undirectional flux (Jms $\mathrm{Na}$ ) (Table 2). Ileal unidirectional chloride fluxes were not significantly altered by glucose but in this group of experiments net $\mathrm{Cl}$ absorption was significantly greater than zero. In the jejunum, unidirectional chloride fluxes were greater in the presence of glucose, but the net value was unchanged. Residual ion flux was not significantly affected by glucose in the ileum or jejunum. The increase in net sodium absorption and SCC produced by glucose was greater in the ileum than the jejunum.

\section{Discussion}

These results are broadly similar to those reported with in vitro animal intestine. They differ, however, in several important respects from those obtained in vivo in man and animals and it is clear that technical rather than species differences are responsible for many of the discrepancies between in vivo human and in vitro animal intestinal behaviour.

\section{JEJUNUM}

There have been difficulties in demonstrating transport of sodium against electrochemical gradients in the human jejunum in vivo (Fordtran et al., 1968; Turnberg et al., 1970b), probably because of the high mucosal permeability to sodium which prevents the development of concentration gradients. The present studies and those of Binder (1974), however, do demonstrate that human jejunal mucosa can transport sodium actively in vitro in glucose-free solutions. Glucose enhanced sodium absorption, as in vivo, and the rise in SCC was entirely attributable to this effect on sodium transport.

The absence of a significant net chloride movement in short-circuited jejunal mucosa is compatible with similar observations in vivo where all chloride movement appears to be a passive consequence of electrochemical gradients (Fordtran et al., 1968). Glucose had no effect on net chloride transport, although both unidirectional fluxes were increased, presumably associated with the lower tissue resistance in the presence of glucose.

Significant bicarbonate movement as judged by the residual ion flux, was not seen, although in vivo studies in man have demonstrated jejunal absorption of bicarbonate against a considerable electrochemical gradient (Turnberg et al., 1970b). It is likely that factors such as $\mathrm{pH}, \mathrm{PCO}_{2}$, and $\mathrm{HCO}_{3}$ gradients, which are present in vivo but usually excluded in vitro, may explain these differences.

Fromm (1973) demonstrated that short-circuited rabbit jejunum in vitro secreted sodium and bicarbonate, while chloride movement was negligible. These differences in sodium and bicarbonate movement between human and rabbit jejunum presumably reflect species differences.

\section{ILEUM}

We have confirmed the experimental observation in human and animal tissue that sodium absorption occurs against an electrochemical gradient in the ileum in vitro (Grady et al., 1967; Field et al., 1971; Al-Awqati et al., 1973) and in vivo (Fordtran et al., 1968; Turnberg et al., 1970a).

However, net absorption of chloride by ileal mucosa was demonstrated in only some of the present studies. For example, it was not demonstrated in the control investigations in the absence of glucose but in the presence of glucose net chloride absorption became significant (Table 2). This variability could conceivably be due to variations in preoperative drug therapy and anaesthesia but it is of interest that a similar variability has been remarked on by several workers in animal experiments where this possible source of variation is obviated (Schultz et al., 1964; Binder et al., 1973; Al-Awqati et al., 1973; Nellans et al., 1975). It has been suggested that some of this variability might be due to variations in mucosal adenyl cyclase activity or cyclic 3', 5', adenosine monophosphate concentrations but there is no firm evidence in support of this (Nellans et al., 1974).

This demonstration of active sodium and chloride absorption in vitro confirms the in vivo behaviour of human ileum (Fordtran et al., 1968; Turnberg et al., 1970a). Ileal residual ion fluxes suggested bicarbonate secretion (or hydrogen absorption) in glucose-free solutions, as has been demonstrated in man in vivo (Turnberg et al., 1970a) and in animals in vitro (Field et al., 1971; Dietz and Field, 1973).

Glucose enhanced net sodium absorption as in animal ileum (Schultz and Zalusky, 1964b; Field et al., 1971; Fromm, 1975), and the increase in 
sodium absorption was greater in ileum than jejunum. This observation is apparently dissimilar from the in vivo ileal response (Fordtran et al., 1968) where significant stimulation of sodium absorption is not observed.

\section{COMPARISONS BETWEEN JEJUNUM AND}

\section{ILEUM}

It is clear that in vivo (Fordtran et al., 1968; Turnberg et al., 1970a, b), human jejunum and ileum behave differently towards water and electrolytes. Thus, in vivo jejunal mucosa is much more permeable to water and small ions than ileal mucosa (Fordtran et al., 1965). Thus, it might have been predicted that in vitro unidirectional fluxes, especially of sodium, would be higher in jejunum than ileun, and electrical PD and tissue resistance higher in ileum than jejunum. However, the reverse situation was observed and unidirectional fluxes of $\mathrm{Na}$ and $\mathrm{Cl}$ were lower in jejunal than ileal mucosa.

This paradoxical finding of a higher ileal permeability is difficult to explain but it seems likely that it is due to differences in experimental conditions between in vivo and in vitro studies. Conceivably mucosa from one region of the intestine changes its function relative to the other on transfer to the in vitro situation. In support of this is the observation here that the presence of glucose in the bathing media was associated with a significant fall in jejunal resistance over a 50 minute period suggesting an effect on permeability not observed in ileal mucosa and indicating differing responsiveness to in vitro experimental conditions. Whatever the cause for these discrepancies between in vitro and in vivo studies, they do suggest the need for caution in relating results obtained in vitro to the in vivo situation.

We are grateful to $\mathrm{Mr}$ H. B. Torrance, Mr J. B. Elder and Professor M. H. Irving for their kind co-operation in providing the operative specimens. This work was supported by grants from the Medical Research Council and the Welcome Trust.

Some of this work was reported at a Falk symposium on Intestinal Ion Transport in Titisee, May 1975. (Intestinal. Ion Transport, Ed Robinson W. L. (1976) M.T.P. Press, G.B.).

\section{References}

Al-Awqati, Q., Cameron, J. L., and Greenough, W. E.
(1973). Electrolyte transport in human ileum: effect of purified cholera exotoxin. American Journal of Physiology, 224, 818-823.

Binder, H. J. (1974). Sodium transport across isolated human jejunum. Gastroenterology, 67, 231-236.

Binder, H. J., Powell, D. W., Tai, Y. H., and Curran, P. F. (1973). Electrolyte transport in rabbit ileum. American Journal of Physiology, 225, 776-780.

Dietz, J., and Field, M. (1973). Ion transport in rabbit ileal mucosa. 4. Bicarbonate secretion. American Journal of Physiology, 225, 858-861.

Field, M., Fromm, D., and McColl, I. (1971). Ion transport in rabbit ileal mucosa. 1. $\mathrm{Na}$ and $\mathrm{Cl}$ fluxes and short circuit current. American Journal of Physiology, 220, 1388-1396.

Fordtran, J. S., Rector, F. C., and Carter, N. W. (1968). The mechanisms of sodium absorption in the human small intestine. Journal of Clinical Investigation, 47, 884-900.

Fordtran, J. S., Rector, F. C. ,Ewton, M. F., Soter, N., and Kinney, J. (1965). Permeability characteristics of the human small intestine. Journal of Clinical Investigation, 44, 1935-1944.

Fromm, D. (1973). $\mathrm{Na}$ and $\mathrm{Cl}$ transport across isolated proximal small intestine of the rabbit. American Journal of Physiology, 224, 110-116.

Glew, R. H., Moore, E. J., and Wallace, C. K. (1973). Short circuit current across isolated rabbit ileum, jejunum and duodenum. Proceedings of the Society of Experimental Biology and Medicine, 142, 857-860.

Grady, G. F., Madoff, M. A., Duhamel, R. C., Moore, E. W., and Chalmers, T. C. (1967). Sodium transport by human ileum in vitro and its response to cholera enterotoxin. Gastroenterology, 53, 737-744.

Nellans, H. N., Frizzell, R. A., and Schultz, S. G. (1974). Brush-border processes and transepithelial $\mathrm{Na}$ and $\mathrm{Cl}$ transport by rabbit ileum. American Journal of Physiology, 226, 1131-1141.

Nellans, H. N., Frizzell, R. A., and Schultz, S. G. (1975). Effect of acetazolamide on sodium and chloride transport by in vitro rabbit ileum. American Journal of Physiology, 228, 1808-1814.

Schultz, S. G., and Zalusky, R. (1964a). Ion transport in isolated rabbit ileum. 1. Short circuit current and sodium fluxes. Journal of General Physiology, 47, 567-584.

Schultz, S. G., and Zalusky, R. (1964b). Ion transport in isolated rabbit ileum. 2. The interaction between active sodium and active sugar transport. Journal of General Physiology, 47, 1043-1059.

Schultz, S. G., Zalusky, R., and Gass, A. E. (1964). Ion transport in isolated rabbit ileum. 3. Chloride fluxes. Journal of General Physiology, 48, 375-378.

Turnberg, L. A., Bieberdorf, F. A., Morawski, S. G., and Fordtran, J. S. (1970a). Interrelationships of chloride, bicarbonate, sodium and hydrogen transport in the human ileum. Journal of Clinical Investigation, 49, 557567.

Turnberg, L. A., Fordtran, J. S., Carter, N. W., and Rector, F. C. (1970b). Mechanisms of bicarbonate absorption and its relationship to sodium transport in the human jejunum. Journal of Clinical Investigation, 49, 548-556. 